\title{
Influência da caseína hidrolisada no cultivo in vitro de Oncidium baueri (Orchidaceae)
}

\section{Influence of hydrolized casein on the Oncidium baueri (Orchidaceae) in vitro cultivation}

\author{
José Geraldo Zaparolli Vieira'; ${ }^{1}$ Jorge Kaoro Yamakami1'; Ricardo Sfeir de Aguiar'; \\ Lilian Keiko Unemoto²; Ricardo Tadeu de Faria ${ }^{3 *}$
}

\section{Resumo}

O nitrogênio possui grande importância para a maioria das espécies cultivadas in vitro. Está envolvido nos processos fisiológicos e bioquímicos associados ao controle de crescimento, diferenciação e morfogênese, sendo a caseína uma das principais fontes de suplementação do nitrogênio. $\mathrm{O}$ objetivo deste trabalho foi avaliar a influência de diferentes concentrações de caseína hidrolisada no crescimento vegetativo e enraizamento in vitro de Oncidium baueri (Orchidaceae). Os tratamentos testados foram: T1- 0,0 g.L.- ${ }^{-1}$; T2- 0,5 g.L $\mathrm{L}^{-1}$ de caseína hidrolisada; T3- 1,0 g.L.-1 de caseína hidrolisada; T4- 2,0 g.L.- de caseína hidrolisada e T5- 4,0 g. $\mathrm{L}^{-1}$ de caseína hidrolisada. O meio de cultura utilizado foi o Murashige e Skoog (1962), modificado com metade da concentração de macronutrientes. Após seis meses do início do experimento foram avaliados: massa fresca total; altura da parte aérea; comprimento da maior raiz; número de raízes e número de brotações laterais. Não se observou efeito benéfico no desenvolvimento vegetativo e radicular de Oncidium baueri em meio de cultura suplementado com caseína hidrolisada. A porcentagem de sobrevivência foi $100 \%, 95 \%$ e $94 \%$, respectivamente para T1, T2 e T3, e $80 \%$ para T4 e T5.

Palavras-chave: Nitrogênio, orquídea, cultura de tecidos

\begin{abstract}
The nitrogen is essentially important for most in vitro cultivated species. It is regarded to the physiological and biochemical processes involved in growth control, differentiation and morphogenesis, and casein is one of the main nitrogen supplementation sources. The objective of this work was to evaluate the influence of different concentrations of hydrolized casein on the in vitro vegetative growth and rooting of Oncidium baueri (Orchidaceae). The treatments tested were: T1- 0.0 g.L.- $;$ T2- 0.5 g.L.-1 $;$ T3- 1.0 g. L ${ }^{-1}$; T4 -2.0 g.L $\mathrm{L}^{-1}$; T5- 4.0 g.L. $\mathrm{L}^{-1}$ of hydrolized casein. The culture medium used was the Murashige and Skoog modified with half macronutrients concentration. Total fresh mass, aerial part height, biggest root length, roots number and lateral sprouts number were evaluated after six months from the beginning of the experiment. It was not detected any beneficial effects of casein on vegetative and root development of Oncidium baueri. The percentage of surviving plants was $100 \%, 95 \%$ and $94 \%$, respectively for T1, T2 and $\mathrm{T} 3$, and $80 \%$ of surviving plants for T4 and T5.
\end{abstract}

Key words: Nitrogen, orchid, tissue culture

\footnotetext{
1 Eng $^{\mathrm{o}} \mathrm{Agr}^{\circ}$. Mestre em Agronomia, Universidade Estadual de Londrina, PR

2 Bióloga. Mestre em Fitotecnia, Universidade Estadual de Londrina, PR.

3 Eng. $^{\circ}$ Agr ${ }^{\circ}$. Prof. Adjunto. Depto. Agronomia. UEL, Londrina. PR. E-mail: faria@uel.br.

* Autor para correspondência
} 


\section{Introdução}

A propagação in vitro de orquídeas é de grande importância por possibilitar a obtenção de um grande número de mudas em pequeno espaço físico, em pouco tempo e com grande qualidade fisiológica e sanitária (ALTAFIN et al., 2003).

O sucesso na tecnologia e aplicação dos métodos de cultura in vitro deve-se a uma melhor compreensão dos requerimentos nutricionais das células e tecidos em cultura. A formulação do meio de cultura é essencial para a planta, pois concentra os nutrientes necessários para seu desenvolvimento, podendo ser formulado com diferentes combinações de acordo com os requerimentos de cada espécie (FARIA et al., 2002).

O metabolismo do nitrogênio está envolvido nos processos fisiológicos e bioquímicos associados ao controle de crescimento, diferenciação e morfogênese. Durante o crescimento celular, a assimilação do nitrogênio contribui para o aumento de macromoléculas e componentes celulares, importantes para a regulação dos processos metabólicos do crescimento celular, implicando no aumento de tamanho e número de células (DURZAN, 1985), sendo um nutriente de grande importância para a maioria das espécies cultivadas in vitr. A caseína hidrolisada é uma das principais fontes de suplementação deste elemento no cultivo in vitro de orquídeas (BAGDE; SHARON, 1997; VIJ; KAUR, 1998), cana-de-açúcar (SILVA et al., 1997) e cravo (HAYASHI et al., 2002).

As formas orgânicas de nitrogênio utilizadas em cultura de tecidos incluem misturas complexas de compostos nitrogenados, como extrato de levedura, extrato de malte e caseína hidrolisada, estimulando o crescimento de muitas espécies quando cultivadas in vitro. Estas misturas fornecem um conjunto de aminoácidos que estimulam o crescimento de muitas espécies in vitro e dependendo da espécie, pode ser observado estímulo ou inibição do crescimento e do desenvolvimento, quando um aminoácido é acrescido isoladamente ou em mistura (TORRES; CALDAS; BUSO, 1998).

Segundo De Lucca (2003), a qualidade da cultura é afetada consideravelmente sem caseína hidrolisada, reduzindo a capacidade regenerativa da planta quando empregada na indução e multiplicação de calos embriogênicos somáticos de milho.

O presente trabalho teve como objetivo avaliar a influência da adição de caseína hidrolisada no crescimento vegetativo e enraizamento in vitro de Oncidium baueri.

\section{Material e Métodos}

As plântulas de Oncidium baueri Lindl. foram obtidas por semeadura in vitro, seguindo a metodologia descrita por Faria e Illg (1998). Após as plântulas atingirem aproximadamente, $1,0 \pm 0,5 \mathrm{~cm}$ de altura, foram subcultivadas para os seguintes tratamentos contendo caseína hidrolisada: T1- 0,0 g.L-1 $;$ T2-0,5g.L-1; T3- 1,0 g.L L $^{-1}$, T4- 2,0 g.L ${ }^{-1}$ e T5- 4,0 g.L - $^{-1}$.

O meio de cultura utilizado foi o MS (MURASHIGE; SKOOG, 1962) modificado com metade da concentração dos macronutrientes e suplementado com 1 g.L $\mathrm{L}^{-1}$ de carvão ativado. O meio de cultura foi distribuído em frascos de $250 \mathrm{~mL}$ contendo aproximadamente $50 \mathrm{~mL}$ de meio de cultura por frasco. O meio foi solidificado com 7,0 g. $\mathrm{L}^{-1}$ de ágar e o pH ajustado para 6,0 com solução de $\mathrm{KOH}$, antes do processo de autoclavagem a $121^{\circ} \mathrm{C}$ e 1 atm por 20 minutos.

$\mathrm{O}$ experimento foi conduzido em câmara de crescimento com temperatura de $25^{\circ} \pm 2^{\circ} \mathrm{C}$ e fotoperíodo de 16 horas luz com intensidade luminosa $35 \mu \mathrm{mol} . \mathrm{m}^{-2} \mathrm{~s}^{-1}$.

Após seis meses do início do experimento foram avaliados: massa fresca total (g), altura da parte aérea $(\mathrm{cm})$, comprimento da maior raiz $(\mathrm{cm})$, número de raízes e número de brotações laterais. As mudas tiveram suas raízes lavadas em água corrente para remoção do meio de cultura e foram aclimatizadas 
em bandejas de isopor contendo fibra de coco como substrato. As plântulas foram mantidas em casa de vegetação com 50\% luminosidade, regadas diariamente de forma manual e adubadas semanalmente com 3,0 g.L $\mathrm{L}^{-1}$ de adubo foliar NPK 66-8. A avaliação da porcentagem de sobrevivência foi realizada após seis meses do transplantio das mudas para a casa de vegetação.

O delineamento experimental utilizado foi o inteiramente casualizado, com dez repetições contendo oito plantas por repetição. Os dados foram submetidos à análise de variância, complementados pelo teste de Tukey a 5\% de significância.

\section{Resultados e Discussão}

Os tratamentos sem caseína ou em concentrações de até 2,0 g.L.-1 (T1, T2, T3 e T4) foram os que apresentaram as maiores médias para todas as variáveis analisadas (Tabela 1), embora não apresentem diferenças estatísticas entre si.

Tabela 1. Valores médios de matéria da massa fresca total, altura da parte aérea, comprimento da maior raiz, número de raízes e número de brotações laterais, para a orquídea Oncidium baueri Lindl. após quatro meses do início do experimento.

\begin{tabular}{|c|c|c|c|c|c|}
\hline $\begin{array}{c}\text { Caseína } \\
\text { Hidrolisada } \\
\left(\mathrm{g} . \mathrm{L}^{-1}\right)\end{array}$ & $\begin{array}{c}\text { Massa Fresca } \\
\text { Total } \\
\text { (g) }\end{array}$ & $\begin{array}{c}\text { Altura da } \\
\text { Parte Aérea } \\
\text { (cm) }\end{array}$ & $\begin{array}{l}\text { Comprimento da } \\
\text { Maior Raiz } \\
\text { (cm) }\end{array}$ & $\begin{array}{l}\text { Número de } \\
\text { Raízes }^{2}\end{array}$ & $\begin{array}{c}\text { Número de } \\
\text { Brotações } \\
\text { Laterais }^{2}\end{array}$ \\
\hline ( T1) 0,0 & $0,17 a^{1}$ & $3,55 \mathrm{a}$ & $3,93 \mathrm{a}$ & $6,93 \mathrm{a}$ & $1,70 \mathrm{a}$ \\
\hline (T2) 0,5 & $0,15 \mathrm{ab}$ & $3,24 \mathrm{ab}$ & $2,87 \mathrm{ab}$ & $5,58 \mathrm{ab}$ & $1,60 \mathrm{a}$ \\
\hline (T3) 1,0 & $0,14 \mathrm{ab}$ & $3,29 \mathrm{ab}$ & $3,27 \mathrm{ab}$ & $5,73 \mathrm{a}$ & $1,63 \mathrm{a}$ \\
\hline (T4) 2,0 & $0,14 \mathrm{ab}$ & $3,22 \mathrm{ab}$ & $2,84 \mathrm{ab}$ & $5,22 \mathrm{ab}$ & $1,65 \mathrm{a}$ \\
\hline (T5) 4,0 & $0,10 \mathrm{~b}$ & $2,19 \mathrm{~b}$ & $2,05 \mathrm{~b}$ & $4,45 \mathrm{c}$ & $1,23 \mathrm{~b}$ \\
\hline $\mathrm{CV} \%$ & 27,76 & 23,35 & 29,43 & 17,99 & 23,29 \\
\hline
\end{tabular}

${ }^{1}$ Médias seguidas pela mesma letra na vertical não diferem entre si pelo teste Tukey no nível de 5\%.

${ }^{2}$ dados sob transformação raiz quadrada de $\mathrm{y}+0,5$.

Para as variáveis: massa fresca total e altura da parte aérea, as plântulas que foram cultivadas na ausência de caseína apresentaram médias superiores em relação às plantas que foram cultivadas em $\mathrm{T} 5$ $\left(4,0\right.$ g.L $\left.\mathrm{L}^{-1}\right)$, porém não foi possível verificar diferenças significativas entre T1, T2, T3 e T4 $(0,0 ; 0,5 ; 1,0 ; 2,0$ g. $\mathrm{L}^{-1}$ de caseína). Para o comprimento da maior raiz, embora as plântulas cultivadas em T1 e T3 apresentarem as maiores médias, não foram verificadas diferenças significativas entre os tratamentos (Figura 1).

As plântulas dos tratamentos T1, T2, T3 e T4, apresentaram maior número de raízes e número de brotações laterais, em relação às plântulas que foram cultivadas em T5 (4,0 g.L.-1 $)$, fato este que demonstra que a adição de altas concentrações de caseína ao meio de cultura pode ter influenciado negativamente o desenvolvimento da espécie em estudo.

Badge e Sharon (1997) utilizaram a adição da caseína hidrolisada na concentração de $200 \mathrm{mg} . \mathrm{L}^{-1}$ e $15 \%$ de água de coco ao meio de cultura VW (VACIN; WENT, 1964), observando uma alta freqüência de proliferação de protocormos e aumento da massa fresca total na regeneração in vitro de Oncidium. 


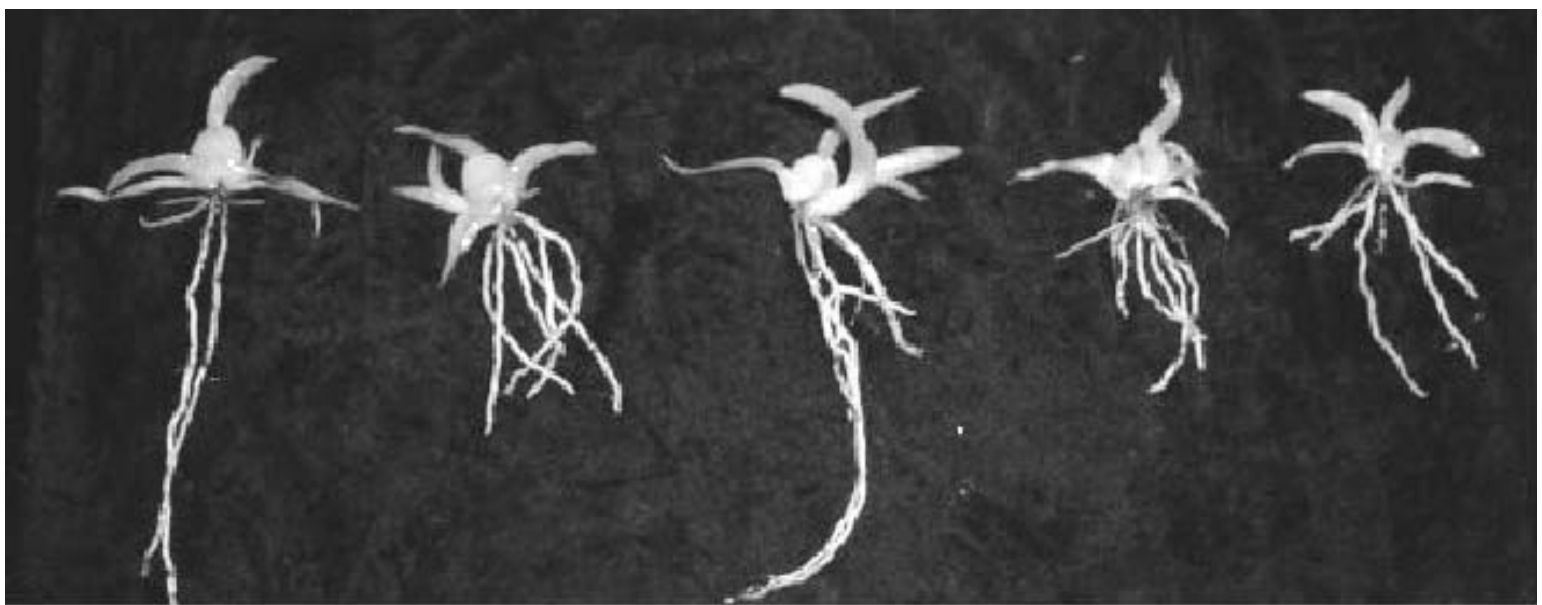

Figura 1. Crescimento vegetativo e desenvolvimento radicular das plântulas de Oncidium baueri após seis meses de cultivo nos diferentes tratamentos. Legenda: T1- 0,0 g. $\mathrm{L}^{-1}$ de caseína hidrolisada; T2- 0,5 g.L $\mathrm{L}^{-1}$ de caseína hidrolisada; T3- 1,0 g.L $\mathrm{L}^{-1}$ de caseína hidrolisada; T4- 2,0 g.L $\mathrm{L}^{-1}$ de caseína hidrolisada e T5- 4,0 g.L $\mathrm{L}^{-1}$ de caseína hidrolisada. Da esquerda para direita respectivamente.

Dantas et al. (2002) trabalhando com embriões de macieira in vitro no meio MS suplementado com AIA, GA3 e $500 \mathrm{mg} . \mathrm{L}^{-1}$ de caseína hidrolisada observaram que não houve diferença estatística para o comprimento das brotações entre os tratamentos. Entretanto, a maior porcentagem de germinação (75\%) foi obtida no tratamento com AIA $(14 \mu \mathrm{M})$, $\mathrm{GA}_{3}(1,5 \mu \mathrm{M})$, caseína hidrolisada $\left(500 \mathrm{mg} \mathrm{L}^{-1}\right)$ e cinetina $(5 \mu \mathrm{M})$. Raganwamy, (1961) relatou que a caseína hidrolisada (400 $\left.\mathrm{mg} \mathrm{L}^{-1}\right)$ foi essencial para germinação de embriões de Citrus microcarpa X Triticosecale, Oriza sativa e Prunus persica.

Um outro fator importante a ser verificado neste estudo é a proporção de pegamento ex vitro das plântulas na fase de aclimatização. A aclimatização é a fase da micropropagação em que ocorre a transferência das mudas produzidas in vitro para o ambiente externo, a casa-de-vegetação (DEBERG; MAENE, 1981). De acordo com Costa (1998), a fase de aclimatização é muito delicada porque além de representar um estresse para a plântula, existe o risco de infecções por fungos e bactérias. Um grande número de plantas micropropagadas não sobrevive quando transferidas das condições in vitro para o ambiente externo; porém, um fator importante para amenizar esse problema é a obtenção de plântulas sadias com sistema radicular e parte aérea proporcionais, a fim de atingir maior freqüência de pegamento.

A porcentagem de sobrevivência das mudas aclimatizadas foi de $100 \%, 95 \%$ e $94 \%$ para os tratamentos T1, T2 e T3, respectivamente, enquanto que nas concentrações maiores de caseína hidrolisada T4 e T5, a porcentagem de sobrevivência das plântulas foi reduzida significativamente para $80 \%$ (Tabela 2), demonstrando não haver aumento da sobrevivência com caseína, podendo a mesma ser prejudicial acima de 2,0 g.L $\mathrm{L}^{-1}$.

Tabela 2. Porcentagem sobrevivência de plantas de Oncidium baueri após seis meses da fase de aclimatização.

\begin{tabular}{ccccccc}
\hline $\begin{array}{c}\text { Caseína Hidrolisada } \\
\left(\mathrm{g} . \mathrm{L}^{-1}\right)\end{array}$ & $(\mathrm{T} 1) 0,0$ & (T2) 0,5 & (T3) 1,0 & (T4) 2,0 & (T5) 4,0 & CV (\%) \\
\hline $\begin{array}{c}\text { Porcentagem de } \\
\text { Sobrevivência }\end{array}$ & $100 \mathrm{a}^{1}$ & $95 \mathrm{a}$ & $94 \mathrm{a}$ & $80 \mathrm{~b}$ & $80 \mathrm{~b}$ & 18 \\
\hline
\end{tabular}

${ }^{1}$ Médias seguidas pela mesma letra não diferem entre si pelo teste de Tukey ao nível de 5\%. 


\section{Conclusão}

A suplementação do meio de cultura com caseína hidrolisada, nas concentrações utilizadas, não foi benéfica para o crescimento vegetativo e enraizamento in vitro bem como para a sobrevivência ex vitro de Oncidium baueri.

\section{Referências}

ALTAFIN, R. L. M.; MENEZES, M. O.; LIMA, R. R. F.; PITOMBO, L. M. Semeadura in vitro de orquídeas para propagação massal, Boletim Técnico, Espírito Santo do Pinhal, n.7, p., 2003.

BAGDE, P.; SHARON, M. In vitro regeneration of Oncidium Gower Ramsey by high frequency protocorm like bodies proliferation. Indian Journal of Plant Physiology, New Delhi, v.2, n.1, p.10-14, 1997.

COSTA, A. M. M. Fisiologia da aclimatização. In: TOMBOlATO, A. F. C.; COSTA, A. M. M. Micropropagação de plantas ornamentais. Campinas: Instituto Agronômico, 1998. p.63-67.

DANTAS, A. C. M.; MORAES, L. K. A.; PEDROTTI, E. L.; . NODARI, R. O.; GUERRA, M. P. Superação in vitro da dormência de embriões do porta-enxerto de macieira M9 (Malus pumilla Mill.). Revista Brasileira de Fruticultura, Cruz das almas, v.24, n.1, p.10-14, 2002.

DE LUCCA, P. C. Produção dos hormônios recombinantes de crescimento e pró-insulina humanos em plantas transgênicas de milho. 2003. Tese (doutorado) - Universidade Estadual de Campinas. Instituto de Biologia, Campinas.

DEBERGH, P. C.; MAENE, L. V. A scheme for commercial propagation of ornamental plants by tissue culture. Scientia Horticulturae, Amsterdam, v.14, p.335-345, 1981.

DURZAN, D. J. Nitrogen metabolism and vegetative propagation of forest trees. In: BONGA, J. M.; DURZAN, D. J. (Ed.) Tissue culture in forestry. Dordrecht: Martinus Nijhoff, 1985. cap.10, p.256-324.
FARIA, R. T.; ILLG, R. D. Orquídea Dendrobium nobile . In: TOMBOLATO, A. F. C.; COSTA, A. M. M. Micropropagação de plantas ornamentais. Campinas: Instituto Agronômico, 1998. p.34-36.

FARIA, R. T.; SANTIAGO, D. C.; SARIDAKIS, D. P.; ALBINO, U. B.; ARAÚJO, R. Preservation of the brazilian orchid Cattleya walkeriana Gardner using in vitro propagation. Crop Breeding and Applied Biotechnology, Viçosa, v.2, n.3, p.489-492, 2002.

HAYASHI, T. K.; MOREIRA, A.; AMARAL, A. F. C.; MELO, M. Tratamento de matrizes de cravo (Dianthus caryophillus L., Caryophyllaceae) com nitrogênio e calogênese in vitro. Scientia Agrícola, Piracicaba, v.59, n.1, p.47-52, 2002.

MURASHIGE, T.; SKOOG, F. A revised medium for rapid growth and bioassays with tobacco tissue culture. Physiologia Plantarum, Copenhagen, v.15, p.473-497, 1962.

RAGANWAMY, N. S. Experimental studies on female reproductive structures of Citrus microcarpa Bunge. Phytomorphology, New Delhi, v.11, p.109-127, 1961.

SILVA, J. G. F.; DONATO, V. M. T. S.; MACIEL, G. A; FRANÇA, J. G. E. Avaliação do comportamento in vitro de duas variedades de cana-de-açúcar (CB45-3, RB732577) na presença de caseína hidrolisada. In: CONGRESSO BRASILEIRO DE GENÉTICA, 43., 1997, Goiânia. Anais... Goiânia: SBG, 1997.

TORRES, A. C.; CALDAS, L. S.; BUSO, J. A. Cultura de tecido e transformação genética de plantas. Brasília: Embrapa, 1998.

VACIN, E. T.; WENT, F. W. pH changes in nutrient solutions. Botanical Gazette, Chicago, v.110, p.605-613, 1964.

VIJ, S. P.; KAUR, S. Micropropagation of therapeutically important orchids: Malaxis acuminata D. Don. Journal of the Orchid Society of India, Bangalore, v.12, n.1/2, p.8993, 1998. 
